\title{
PENGARUH PEMBERIAN PUPUK KANDANG SAPI DAN PUPUK TSP TERHADAP PERTUMBUHAN DAN HASIL TANAMAN JAGUNG MANIS (Zea mays saccharata L.)
}

\author{
Oleh*Sunaldi** Ir. Hj. Fiana podesta, MP dan dwi fitriani, SP. MP \\ (Alumni FP UMB dan **dosen FP UMB)
}

\begin{abstract}
ABSTRAK
Jagung manis (Zea mays saccharata L.) merupakan salah satu jenis tanaman jagung yang belum lama dikenal dan berkembang di Indonesia. Salah satu faktor yang menjadi kendala dalam pengembangan jagung manis karena keterbatasan lahan produktif, dan fungsinya telah berubah. Sebagai upaya peningkatan produksi jagung manis pada umumnya terkendala oleh lahan yang tidak subur dan petani harus mampu memanfaatkan lahan yang tidak subur untuk mencapai hasil yang maksimal, misalnya penggunaan pupuk sapi dan TSP. Penelitian ini bertujuan untuk mengetahui pengaruh sapi dan pupuk TSP terhadap pertumbuhan dan hasil jagung manis (Zea mays saccharata L.). Penelitian ini menggunakan Rancangan Acak Kelompok (RAK) faktorial dengan dua faktor dan 3 ulangan. Faktor perlakuan pertama adalah pemberian pupuk sapi (S), terdiri dari 3 taraf S0 (0 ton / ha), S1 (15 ton / ha), S2 (30 ton / ha). Faktor perlakuan kedua adalah pupuk TSP (P) yang terdiri dari 3 taraf yaitu P0 (0 kg / ha), P1 (50 kg / ha), P2 (100 kg / ha).

Data dianalisis secara statistik dengan menggunakan analisis varian dalam terang Duncan's Multipe Range Test (DMRT), pada taraf 5\%. Pemberian pupuk sapi sangat berpengaruh nyata pada tanaman jagung manis 8 MST, diameter batang $8 \mathrm{MST}$, jumlah daun $8 \mathrm{MST}$, umur berbunga, panjang tongkol, diameter tongkol, bobot tongkol tongkol dan bobot tongkol tanpa tongkol. Pemberian pupuk TSP tidak berpengaruh nyata terhadap bobot tongkol tanpa kelobot. Pengaruh yang signifikan terhadap bobot sapi, dengan urat yang sama, terhadap tinggi tanaman $8 \mathrm{MST}$, diameter batang $8 \mathrm{MST}$, jumlah daun $8 \mathrm{MST}$, umur berbunga, panjang tongkol dan diameter tongkol. Namun, interaksi yang tidak sama berpengaruh nyata terhadap tinggi tanaman 8 MST dan diameter batang 8 MST. Pengaruh yang sangat nyata terhadap jumlah daun 8 MST, umur berbunga, panjang tongkol, diameter tongkol, bobot tongkol, bobot tongkol dan bobot tongkol tanpa simpul.
\end{abstract}

Kata kunci: Jagung Manis (Zea mays saccharata L.), Pupuk Kotoran Sapi, Pupuk TSP. 


\begin{abstract}
Sweet corn (Zea mays saccharata L.) is a kind of corn plant that has not been long known and developed yet in Indonesia. One of the factors becomes a obstacle for developing the sweet corn due to the limited productive land, and its function has been changed. As an effort for increasing sweet corn production is generally constrained by infertile land and farmers should be able to utilize infertile land to achieve maximum results, for instance the use of cow and TSP fertilizer. This study aims to determine the effect of cow and TSP fertilizer on the growth and sweet corn results (Zea mays saccharata L.). This research used factorial randomized block design with two factors and 3 replications. The first, treatment factor was the granting of Cow fertilizer (S), which consisted of 3 levels of $\mathrm{S}_{0}$ (0 tons/ha), S1 (15 tons/ha), S2 (30 tons/ ha). The second, treatment factor was TSP (P) fertilizer consisting of 3 levels of P0 (0 kg/ha), P1 (50 kg/ha), P2 $(100 \mathrm{~kg} / \mathrm{ha})$.

Data were analyzed statistically by using analysis of variance in the light of Duncan's Multipe Range Test (DMRT), at 5\% level. The cow fertilizer has very significant on sweet corn plants with $8 \mathrm{MST}$, stem diameter of $8 \mathrm{MST}$, number of leaves of $8 \mathrm{MST}$, age of flowering, ear length, ear diameter, ear weight of cornhusk and weight of ear without cob. The granting TSP fertilizer has not significantly affect the weight of the cob without cornhusk. Its has signigicant affect on the weight of the cow, with the same vein, on plant height $8 \mathrm{MST}$, stem diameter $8 \mathrm{MST}$, number of leaves $8 \mathrm{MST}$, age of flowering, ear length and ear diameter. But, it not the same within interaction significantly affect plant height of $8 \mathrm{MST}$ and stem diameter of $8 \mathrm{MST}$. It had a very significant effect on the number of leaves of $8 \mathrm{MST}$, flowering age, ear length, ear diameter, ear weight, cob weight and weight of cob without knots.
\end{abstract}

Keywords: Sweet Corn (Zea mays saccharata L.), Cow Manure Fertilizer, TSP Fertilizer. 


\section{BAB I PENDAHULUAN}

Tanaman jagung manis (Zea mays saccharata L.) merupakan jenis tanaman jagung yang belum lama dikenal dan dikembangkan di Indonesia. Jagung manis atau sweet corn semakin populer dan banyak dikonsumsi karena memiliki rasa yang lebih manis jika dibanding dengan jagung biasa, aroma yang lebih harum dan megandung gula sukrosa serta rendah lemak sehingga baik untuk dikonsumsi bagi penderita diabetes (Putri, 2011). Jagung manis memberi keuntungan relatif tinggi jika dibudidayakan dengan baik (Sudarsana, 2000).

Berdasarkan Data Badan Pusat Statitsik (BPS) 2016 terjadi penurunan hasil produksi jagung khususnya di Provinsi Bengkulu dalam beberapa tahun terakhir, seperti: Tahun 2012 hasil produksinya adalah 133.770 ton, tahun 2013 hasil produksinya adalah 93.988 ton, tahun 2014 hasil produksinya adalah 72,756 ton, dan tahun 2015 hasil produksinya 52.785. Dari data tersebut menunjukkan penurunan hasil produksi jagung khususnya di Provinsi Bengkulu. Hal ini menjadi fokus dan perhatian pemerintah Provinsi Bengkulu dalam upaya meningkatkan hasil produksi jagung. Perlunya peningkatan hasil produksi jagung dikarenakan tingginya kebutuhan terhadap masyarakat.

Jagung manis adalah termasuk jenis jagung yang paling banyak digemari. Permintaan jagung manis khususnya di Kota Bengkulu sangat tinggi terutama pada awal pergantian tahun. Kebiasaan masyarakat tersebut menuntut tingginya permintaan konsumen terhadap jagung manis di wilayah Provinsi BengkuluSalah satu faktor kendala pengembangan jagung manis adalah terbatasnya lahan produktif akibat adanya alih fungsi. Peningkatan produksi umumnya juga terkendala pada lahan yang kurang subur. Hasil penelitian Dewanto, Londok, Tuturoong, dan Kaunang (2013) menunjukkan adanya pengaruh penggunaan pupuk organik dan non organik terhadap peningkatan hasil produksi jagung. Sehingga petani hendaknya dapat memanfaatkan lahan yang kurang subur untuk mencapai hasil yang maksimal salah satunya dengan penggunaaan pupuk kandang sapi dan pupuk TSP.

Pupuk kandang sapi merupakan jenis pupuk organik yang jumlahnya paling banyak tersedia dibandingkan jenis pupuk kandang lain nya. Pupuk kandang sapi dapat digunakan hampir pada semua tanaman budidaya baik itu tanaman pangan, tanaman hortikultura, maupun tanaman perkebunan. Penambahan bahan organik ke tanah dapat meningkatkan kapasitas tukar kation tanah dan mengurangi kehilangan unsur hara yang ditambahkan melalui pemupukan sehingga dapat meningkatkan ketersediaan hara dalam tanah dan efisiensi pemupukan (Kasno, 2009).

Aplikasi pupuk kandang untuk lahan pertanian tanaman jagung manis yang sudah terlanjur rusak harus lebih dari 5 ton/ha. Dosis 5 ton/ ha-1 per musim tanam adalah untuk kondisi lahan normal. Dalam keadaan lahan sudah rusak dosis yang dianjurkan adalah 20 ton/ha. Kemudian berangsur - angsur diturunkan sampai ke kondisi normal. Dengan demikian, kebutuhan pupuk kandang untuk areal pertanian jagung manis seluas 100 ha sudah mencapai 2.000 ton per musim tanam (Aria, 2009).
Pupuk TSP (Triple Super Posfat) merupakan jenis pupuk 
anorganik yang banyak mengandung unsur fosfor $(\mathrm{P})$. Unsur fosfor adalah unsur hara makro yang dibutuhkan oleh pertumbuhan tanaman dalam jumlah yang cukup besar. Jika dibandingkan dengan beberapa pupuk anorganik sumber $\mathrm{P}$ yang lain, pupuk TSP memiliki kandungan P2O5 lebih tinggi, yaitu mencapai $43-45 \%$ sehingga lebih baik digunakan untuk meningkatkan unsur hara $\mathrm{P}$ pada tanah yang miskin unsur hara fosfat. Dalam tanah lahan kering ketersediaan hara $\mathrm{P}$ umumnya dalam kondisi rendah sampai sedang. Pemberian pupuk $\mathrm{P}$ dalam bentuk TSP pada tanah ultisols sejumlah $40 \mathrm{~kg} / \mathrm{ha}$ dapat meningkatkan kadar P-terekstrak (Purnomo et al, 2001).

Menurut Hanafiah (2005), ketersediaan $\mathrm{P}$ dalam tanah dipengaruhi oleh bahan induk tanah, reaksi tanah $(\mathrm{pH})$, C-organik tanah, dan tekstur tanah. Karena ketersediaannya di dalam tanah, khususnya pada tanah masam yang terbatas sehingga perlu dilakukan upaya penambahan pupuk an organik P guna meningkatkan ketersedi aan $\mathrm{P}$ di dalam tanah. Untuk budidaya tanaman jagung manis dianjur menggunakan jarak tanam 70 x $20 \mathrm{~cm}$ (Fadilah dan Akbar 2015).

\section{Berdasarkan}

uraian

permasalahan di atas, maka perlu dilakukan penelitian secara khusus mengamati pengaruh atau dampak penggunaan pupuk terhadap pertumbuhan jagung manis. Oleh karena itu, akan dilakukan penelitian dengan judul "Pengaruh Pemberian Pupuk Kandang Sapi Dan Pupuk TSP Terhadap Pertumbuhan Dan Hasil Tanaman Jagung Manis (Zea mays saccharata L.).

\section{BAB II \\ METODOLOGI PENELITIAN}

\section{1 waktu dan tempat penelitian}

Penelitian ini dilaksanakan dilahan pertanian yang terletak di Kelurahan Pematang Gubernur, Kecamatan Muara Bangkahulu, Kota Bengkulu, Provinsi Bengkulu. Peneliti an ini dilaksanakan pada November 2019 - Januari 2020.

Alat yang digunakan adalah cangkul, parang, meteran, kayu, ember, gelas ukur, waring, sprayer, jangka sorong, kalkulator, dan alat tulis. Sedangkan bahan yang digunakan adalah benih jagung manis varietas Bonanza F1, pupuk Kandang Sapi, pupuk TSP, pupuk UREA, pestisida Furadan 3GR dan pestisida Regent.

Penelitian ini menggunakan Rancangan Acak Kelompok (RAK) Faktorial dengan dua faktor dan 3 kali ulangan. Faktor perlakuan pertama Pemberian Pupuk Kandang Sapi (S) yang terdiri dari 3 taraf, yaitu: $\mathrm{S} 0=0$ ton/ha, $\mathrm{S} 1=15$ ton/ha , $\mathrm{S} 2=30$ ton/ha. Faktor perlakuan kedua pemberian Pupuk TSP $(\mathrm{P})$ yang terdiri dari 3 taraf, yaitu: $\mathrm{P} 0=0 \quad \mathrm{~kg} / \mathrm{ha}, \mathrm{P} 1=50 \mathrm{~kg} / \mathrm{ha}$, $\mathrm{P} 2=100 \mathrm{~kg} / \mathrm{ha}$.

Dalam penelitian ini terdapat 9 kombinasi perlakuan dan diulang sebanyak 3 kali sehingga memperoleh 27 satuan percobaan. Setiap satuan percobaan terdapat 12 tanaman sehingga memperoleh 324 unit tanaman dan setiap petak percobaan diamati 4 tanaman sampel.

\section{BAB III HASIL DAN PEMBAHASAN}

\subsection{Hasil}

Hasil analisis sidik ragam sesuai dengan parameter yang diamati 
dalam penelitian ini dapat dilihat pada tabel 1 .

Tabel 1. Hasil analisis sidik ragam pengaruh pemberian pupuk kandang sapi dan pupuk TSP serta interaksi terhadap pertumbuhan dan hasil tanaman jagung manis.

\begin{tabular}{lcccc}
\hline \multirow{2}{*}{\multicolumn{1}{c}{ Parameter yang diamati }} & \multicolumn{3}{c}{ F-hitung } & \multirow{2}{*}{ KK \% } \\
\cline { 2 - 4 } & S & $\mathrm{P}$ & $\mathrm{S} \times \mathrm{P}$ & \\
\hline Tinggi tanaman 8 MST & $39,85 *$ & $13,26 * *$ & $1,48 \mathrm{~ns}$ & 11,68 \\
Diameter batang 8 MST & $43,04 * *$ & $10,67 * *$ & $2,30 \mathrm{~ns}$ & 10,43 \\
Jumlah daun 8 MST & $102,60 * *$ & $39,39 * *$ & $9,82 * *$ & 4,25 \\
Umur berbunga & $92,17 * *$ & $30,52 * *$ & $10,11 * *$ & 1,59 \\
Panjang tongkol & $343,12 * *$ & $59,87 * *$ & $61,58 * *$ & 5,25 \\
Diameter tongkol & $3439,37 * *$ & $303,23 * *$ & $265,08 * *$ & 2,44 \\
Berat tongkol berkelobot & $206,83 * *$ & $3,80 *$ & $7,30 * *$ & 14,47 \\
Berat tongkol tanpa kelobot & $211,36 * *$ & $1,27 \mathrm{~ns}$ & $5,63 * *$ & 15,05 \\
\hline
\end{tabular}

\subsubsection{Jumlah daun (helai)}

\subsection{Pembahasan}

\subsubsection{Tinggi tanaman $(\mathrm{cm})$}

Hasil pengamatan dan analisis sidik ragam terhadap tinggi tanaman jagung manis 8 MST menunjukkan bahwa pemberian pupuk kandang sapi dan pupuk TSP berpengaruh sangat nyata terhadap tinggi tanaman jagung manis. Sedangkan interaksi pemberian pupuk kandang sapi dan pupuk TSP berpengaruh tidak nyata pada tinggi tanaman jagung manis.

\subsubsection{Diameter batang $(\mathrm{cm})$}

Hasil pengamatan dan analisis sidik ragam terhadap diameter batang tanaman jagung manis 8 MST menunjukkan bahwa pemberian pupuk kandang sapi dan pupuk TSP berpengaruh sangat nyata terhadap diameter batang tanaman jagung manis. Sedangkan interaksi pemberian pupuk kandang sapi dan pupuk TSP tidak berpengaruh nyata pada diameter batang tanaman jagung manis.
Hasil pengamatan dan analisis sidik ragam terhadap jumlah daun tanaman jagung manis 8 MST menunjukkan bahwa pemberian pupuk kandang sapi dan pupuk TSP berpengaruh sangat nyata terhadap jumlah daun tanaman jagung manis. Sedangkan interaksi pemberian pupuk kandang sapi dan pupuk TSP berpengaruh sangat nyata pada jumlah daun tanaman jagung manis.

\subsubsection{Umur berbunga (hari)}

Hasil pengamatan dan analisis sidik ragam terhadap umur berbunga tanaman jagung manis menunjukkan bahwa pemberian pupuk kandang sapi dan pupuk TSP serta interaksinya berpengaruh sangat nyata terhadap umur berbunga tanaman jagung manis.

\subsubsection{Panjang tongkol (cm)}

Hasil pengamatan dan analisis sidik ragam terhadap panjang tongkol tanaman jagung manis menunjukkan bahwa pemberian pupuk kandang sapi 
serta interaksinya berpengaruh sangat nyata pada panjang tongkol tanaman jagung manis.

\subsubsection{Diameter tongkol $(\mathrm{cm})$}

Hasil pengamatan dan analisis sidik ragam terhadap diameter tongkol tanaman jagung manis menunjukkan bahwa pemberian pupuk kandang sapi dan pupuk TSP serta interaksi berpengaruh sangat nyata pada diameter tongkol tanaman jagung manis.

\subsubsection{Berat tongkol berkelobot $(\mathrm{g})$}

Hasil pengamatan dan analisis sidik ragam terhadap berat tongkol berkelobot tongkol tanaman jagung manis (Lampiran 17) menunjukkan bahwa pemberian pupuk kandang sapi berpengaruh sangat nyata pada berat tongkol berkelobot tanaman jagung manis. Pemberian pupuk TSP berpengaruh nyata terhadap berat tongkol berkelobot tanaman jagung manis. Interaksi pemberian pupuk kandang sapi dan pupuk TSP berpengaruh sangat nyata pada berat tongkol berkelobot tanaman jagung manis.

\subsubsection{Berat tongkol tanpa kelobot (g)}

Hasil pengamatan dan analisis sidik ragam terhadap berat tongkol tanpa kelobot tanaman jagung manis menunjukkan bahwa pemberian pupuk kandang sapi berpengaruh sangat nyata pada berat tongkol tanpa kelobot tanaman jagung manis. Pemberian pupuk TSP berpengaruh tidak nyata pada berat tongkol tanpa kelobot tanaman jagung manis. Interaksi pemberian pupuk kandang sapi dan pupuk TSP berpengaruh sangat nyata pada berat tongkol tanpa kelobot tanaman jagung manis.

\section{BAB IV}

\section{KESIMPULAN}

\section{Kesimpulan}

Berdasarakan hasil penelitian pengaruh pemberian pupuk kandang sapi dan pupuk TSP terhadap pertumbuhan dan hasil tanaman jagung manis (Zea mays saccharata L.) dapat disimpulkan bahwa:

1. Pemberian pupuk kandang sapi terhadap tanaman jagung manis berpengaruh sangat nyata pada tinggi tanaman, diameter batang, jumlah daun, umur berbunga, panjang tongkol, diameter tongkol, berat tongkol berkelobot dan berat tongkol tanpa kelobot.

2. Pemberian pupuk TSP terhadap tanaman jagung manis berpengaruh tidak nyata pada berat tongkol tanpa kelobot. Berpengaruh nyata pada berat tongkol berkelobot. Berpengaruh sangat nyata pada tinggi tanaman, diameter batang, jumlah daun, umur berbunga, panjang tongkol dan diameter tongkol.

3. Interaksi pemberian pupuk kandang sapi dan pupuk TSP terhadap tanaman jagung manis berpengaruh tidak nyata terhadap tinggi tanaman dan diameter batang. Berpengaruh sangat nyata pada jumlah daun, umur berbunga, panjang tongkol, diameter tongkol, berat tongkol berkelobot dan berat tongkol tanpa kelobot.

\section{DAFTAR PUSTAKA}

Adisarwanto dan Widyastuti. 2000. Teknik Bertanam Jagung. Kanisius, Yogyakarta. 
Agustina, L. 2007. Dasar Nutrisi

Tanaman. Penerbit Rineke Cipta. Jakarta.

Al, J. S. 2014. Kandungan Gizi Dan K omposisi Jagung Manis Rebus. Organisasi

Asgar. https://asgar.or.id/health /nutrition-facts/kandungan-gizidan- komposisi-dari-jagungmanis-rebus/. Diakses 25 juni 2019.

Aria, B. 2009. Pengaruh Dosis Pupuk Kandang Dan Frekuensi Pemberian Pupuk Urea Terhadap Pertumbuhan Dan Produksi Jagung (Zea mays L.) Di Lahan Kering. J. Agritrop, 26 (4): 21.

BBPP. 2009. Budidaya Tanaman Jagung Manis. Balai Besar Pelatihan Pertanian, Lembang. http://www.bbpplembang.info/index.php/arsip/ar tikel/artikel-pertanian/515budidaya-tanaman-jagungmanis. Diakses 25 Juni 2019.

BPS. 2016. Tingkat Produksi Jagung Di Provinsi Bengkulu. Data Badan Pusat Statitik Provinsi Bengkulu. htt ps://bengkulu.bps.go.id/statictab le/2016/03/17/257/produksijagung-menurut-kabupatenkota-di-provinsi-bengkulutahun-2010-2015-ton-pipilankering-.html. Diakses 25 Juni 2019.

Budiman, A. 2004. Aplikasi Kascing Dan Cendawan Mikoriza Arbuskula (CMA) Pada Ultisol Serta Efeknya Terhadap Perkembangan

Mikroorganisme Tanah Dan Hasil Tanaman Jagung Semi (Zea mays L.). Skripsi Fakultas Pertanian Universitas Andalas, Padang.
Deptan. 2013. Budidaya Jagung Manis. Departemen

Pertanian, Indonesia. http://epetani.deptan.go.id/budi daya/budidaya-jagung-manis7908.Diakses 25 Juni 2019.

Dewanto, Londok, Tuturoong, dan Kaunang (2013). Pengaruh Pemupukan Anorganik Dan Organik Terhadap Produksi Tanaman Jagung Sebagai Sumber Pakan. Jurnal Zootek Vol. 32, No. 5, 2013. Hlm. 1-8.

Dongoran, D. 2009. Respon Pertumbuhan Dan Produksi Tanaman Jagung Manis (Zea mays sacchara Sturt) Terhadap Pemberian Pupuk Cair TNF Dan Pupuk Kandang Ayam. Skripsi. Fakultas Pertanian Universitas Sumatera Utara. Medan.

Dwidjoseputro, 2006. Pengantar Fisiologi Tumbuhan. Jakarta: Penerbit PT. Gramedia.

Fadilah dan Akbar, K. 2015. Pengaruh Pemberian Pupuk Fosfat Dan Jarak Tanam Yang Tepat Terhadap Pertumbuhan Dan Hasil Tanaman Jagung Manis(Zea mays saccharata stu $r t)$. Agrosamudra, Jurnal Penelit ian. Vol. 2 No. 2.

Hamzah, S. 2014. Pupuk Organik Cair Dan Pupuk Kandang Ayam Berpengaruh Kepada

Pertumbuhan Dan Produksi Kedelai (Glycine max L.). Agrium. 18(3): 228-234.

Hanafiah, K. A. 2005. Dasar-Dasar Ilmu Tanah. Raja Grafindo Persada. Jakarta.

Hartatik, W dan L. R. Widowati. 2006. Pupuk Organik Dan Pupuk Hayati. Balai Penelitian Tanah dan Pengembangan Sumberdaya lahan Pertanian. Bogor. 
Herdiyantoro, D. 2013. Rancangan Aca k Faktorial Acak Lengkap Dan Acak Kelo Mpok. Fakultas Pertanian Universitas Padjadjaran.

Isrun. 2006. Pengaruh Dosis Pupuk P Dan Jenis Pupuk Kandang Terhadap Beberapa Sifat Kimia Tanah, Serapan P Dan Hasil Jagung Manis (Zea mays var saccharata Sturt) Pada Inceptisols Jatinangor. J. Agrisains Vol. 7. No.1:917.

Kasno, A. 2009. Peranan Bahan Organik Terhadap Kesuburan Tanah. Balai Penelitian Tanah, Depaetemen Pertanian, Indonesia.

Kholis, B. M. 2006. Stabilitas fenotipik tiga varietas jagung manis (Zea Mays Saccharata Sturt.) di dataran menengah dan dataran tinggi. Skripsi. Program Studi Pemuliaan Tanaman dan Teknologi Benih, Fakultas Pertanian Institut Pertanian Bogor, Bogor.

Mayadewi. 2007. Pengaruh Jenis Pupuk Kandang Dan Jarak Tanam Terhadap Pertumbuhan Gulma Hasil Jagung Manis. Jurnal Agritop, 26 (4): 153-159.

Novizan, 2005. Petunjuk Pemupukan Yang Efektif. Agromedia Pustaka. Jakarta.

Novriani. 2010. Alternatif Pengelolaan Unsur Hara $P$ (Fosfor) Pada Budidaya Jagung. Agronobis. Jakarta.

Purnomo, J., I G.P. Putu Wigena, dan Djoko Santoso. 2001. Pengaruh takaran fosfor dan bahan organik terhadap kadar dan serapan fosfor pada Tepic Dystropepts di Jambi. Dalam : Prodising Seminar Nasional Sumber Daya tanah, iklim dan
Pupuk. Buku II. Lido-Bogor Hal. 123- 144.

Purwono, M dan Hartono, R. 2007. Bertanam Jagung Manis. Penebar Swadaya. Bogor. 68 hal.

Putri, H. A. 2011. Pengaruh Pemberian Beberapa

Konsentrasi Pupuk Organik Cair Lengkap (POCL) Bio Sugih Terhadap Pertumbuhan dan Hasil Tanaman Jagung Manis (Zea m ays saccharata). Jurnal Ilmiah Pertanian. 8(8):1-8.

Rismunandar, M. dan N. Riski. 2003. Lada Budidaya Dan Tata Niaga. Edisi revisi. Jakarta : Penebar Swadaya.

Setiawan, B. S. 2010. Membuat Pupuk Kandang Secara Cepat. Penebar Swadaya: Jakarta.

Suarni. 2009. Pemanfaatan Jagung Masak Susu Berbagai Produk Olahan Mendukung

Pemenuhan Pangan Menunjang Hidup Sehat. Prosiding Sem Nasional BBP2TP. Palu. p. 175-182.

Subekti, N. A., Syafruddin, R. Efendi, dan S. Sunarti. 2008. Morfologi Tanaman Dan Fase Tanaman Jagung. Balai Penelitian Tanaman Serealia. Maros. 16-28 hal.

Sudarsana, K. 2000. Pengaruh Effective Microorganisme- 4 (EM-4) Dan Kompos Pada Produksi Jagung Manis (Zea mays saccharata) Pada Tanah Enntisols. Jurnal Hortikultura 22(2). 148-155.

Suprapto, H. S. 2004. Bertanam Kedelai. Penebar Swadaya. Jakarta. 
Sutedjo, M. M. 2010. Pupuk dan Cara Pemupukan. Rineka Cipta. Jakarta. 174 hal.

Warisno, 2007. Jagung Hibrida. Kanisius, Yogyakarta.

Widjajanto, D. W., T. Honmura and N. Miyauchi. 2003. Possible Ultilization of Waterh Hyacinth
(Eichhhorniacrassipes (Mart) Solms), an Aquatic Weed, as Green Manure in Vegetables Cropping Systems. Jap. J. Trop Aric. 47 (1): 27-33.

Zulkarnain. 2013. Budidaya Sayuran Tropis. PT Bumi Aksara. Jakarta. 